\title{
Manufacturing Process Optimization to Reduce Rejections of A Support Component
}

\author{
Meenu Minakshi ${ }^{1}$ Sharda Sharma ${ }^{2}$ Dharmendra Kumar Madhukar ${ }^{3}$ \\ ${ }^{I}$ (M. Tech (Research Scholar), Mechanical Engineering, Bansal Institute of Engineering and Technology \\ Lucknow, U.P) \\ ${ }_{2}^{2}$ (Assistant Professor, Mechanical Engineering, Bansal Institute of Engineering and Technology, Lucknow, U.P) \\ ${ }_{3}^{3}$ Assistant Professor, Mechanical Engineering, Surendra Institute of Engineering and Management, Siliguri, \\ W.B.)
}

\begin{abstract}
In the recent days, the demand for high precision components is increasing rapidly, forcing the manufacturing industries to produce component with high surface finish. Because of this reason, today the most challenge of any manufacturing industries is to reduce the rejection as well as rework rate to avoid going into loses.

Keeping in view of the above necessary aspect, this paper is mainly concerned for reducing the rejections to a minimum. In this paper, manufacturing method plan of the support component has been developed in CAM system using NX-CAM software. Process optimization was also carried out by using the mandrel for job holding to reduce the damage of the component while machining operation is running.
\end{abstract}

Keywords: - CAM, Mandrel, Optimization, Spike Support Component, Reduce Rejection, Why-Why Analysis, etc

\section{INTRODUCTION}

CAM Computer-aided manufacturing is the use of computer software to regulate the machine tools and related machinery in the manufacturing of work pieces [1][2][7]. Additionally, it may refer as the utilization of computer which assists in each and every operations of a manufacturing plant, including planning, management, transportation as well as storage[3][4]. Its primary purpose is the creation of faster production process, components and tooling with more precise dimensions and material consistency, in some cases, uses only the required amount of raw material (thus minimizing waste), while at the same time reducing energy consumption. Tool, machining process and methods is being selected which are to be used. Initially, mass-produced things which require machining has been created through the casting or some other non-machine technique [5][6]. This enables the hand-written, short, and highly optimized G-code which may not be created during a CAM package. With regards to the present day and fast emerging industrial world, technology, innovation and robotization is considered to be a major aid for the quick and rapid development of industry [8]. The principle goal of today's manufacturing enterprises is maximum production within the stipulated time by utilizing optimum amount of labor and assets. In modern era, the trends accounts for development of technology includes CNC machining, DNC, FMS, CAD/CAM etc. The development or advancement in these factors, affects the production too much by increasing the quantity as well as the quality and used in improving the defense warheads which incorporates in missiles like AGNI, AKASH, PRUTHVI, THRISHUL, NAG and so on[8]. A missile is a self-propelled guided weapon system consists of 4 system components: targeting and/or guidance, flight system, engine, and warhead.

The manufacturing method plan of the support component is developed in CAM system using NX-CAM software. The support component named as Spike support is used in a fourth generation man-portable fire-and forget anti-tank guided missile with tandem charged heat warhead, developed and designed by the Israeli company and in service with a number of nations. The $2 \mathrm{D}$ input model of spike support component is shown in figure no. 1 and the final $3 \mathrm{D}$ model is illustrated in figure no. 2 


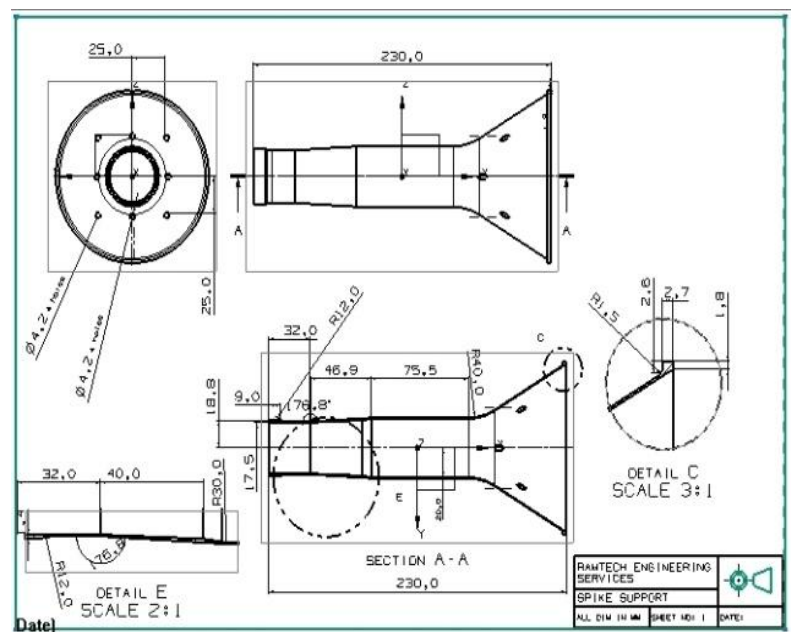

Fig. No. 1: 2D Input of spike support

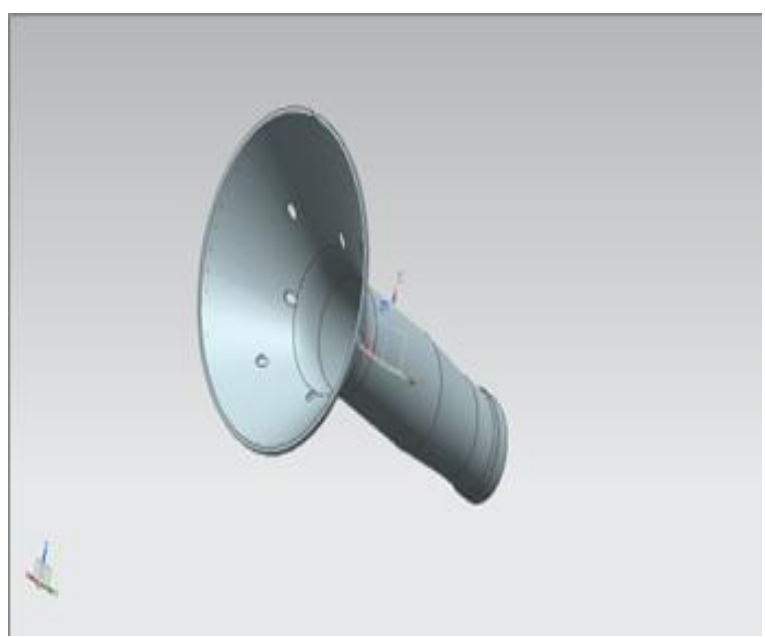

Fig. No. 2: Final 3D model of spike support

The stable speed range for machining the spike support component is $10-30 \mathrm{~Hz}$ i,e $600-1800 \mathrm{rpm}$, has been considered and maintaining this stable speed, spike component is manufactured on CNC machine.

The primary objective of this paper is to reduce the rejection and reworks rate [4] of the Spike support component. The methodology used in manufacturing of the spike support is discussed below:

- Identification of the suitable machine.

- Selection of suitable tools for manufacturing thin walled component.

- Designing of either fixture or mandrel [1][2][3]1 to support spike component for the external operations.

- $\quad$ Listing down the sequence of operations performed on spike component.

- Generating tool path at specified cutting speed.

- Generating NC program using NX-CAM software.

Design of mandrel The mandrel [9][10][11][12] is designed and developed to support the spike component for the internally to allow the high cutting speed. Due to thin wall of component, when an external operations done on it without any support it get damage or form scratches inside. To overcome this, mandrel is designed to reduce the rejection rate as well as to increase the production rate. Mandrel is being modeled by considering an inner dimension of spike component (i.e. inner a dimension of spike component is the outer dimensions of mandrel). Figure no. 3 and 4 shows the 2D input and final 3D design of mandrel.

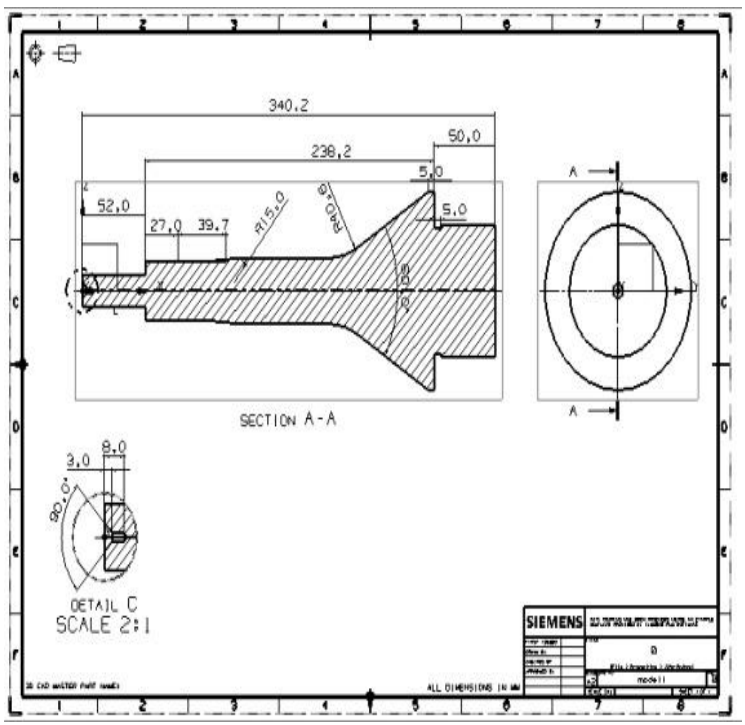

Fig. No. 3: 2D Input of mandrel

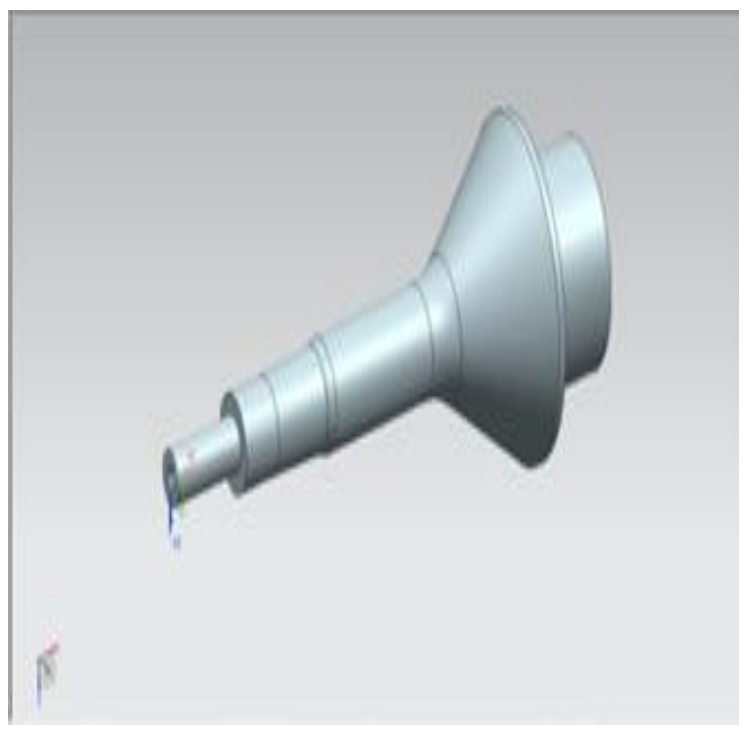

Fig. No. 4: Final 3D model of mandrel 


\section{SEQUENCE OF OPERATIONS PERFORMED ON SPIKE COMPONENT}

ns performed on spike support in NX-CAM software are listed below

Set up-1

$>$ Facing operation

$>$ OD_Rough_Turn operation

$>$ ID_Rough_Bore operation

Set up-2

$>$ Facing operation

$>$ OD_Rough_Turn operation

$>$ Drilling operation

\section{Generation of tool path on spike support}

The series of movements is made by the tip of cutting tools. $\mathrm{X}$ and $\mathrm{Z}$ codes indicates the tool path within a part program. The path through space that the tip of a cutting tool follows on its way to producing the desired geometry of the work piece.

\section{Set_up_1 tool path generation}

Figure no. 5 illustrated below shows the creation of FACING operation on spike model maintaining speed at $1200 \mathrm{rpm}$ and feed $0.25 \mathrm{~mm} /$ revolution. Figure no. 6 shows the verification of the facing operation.

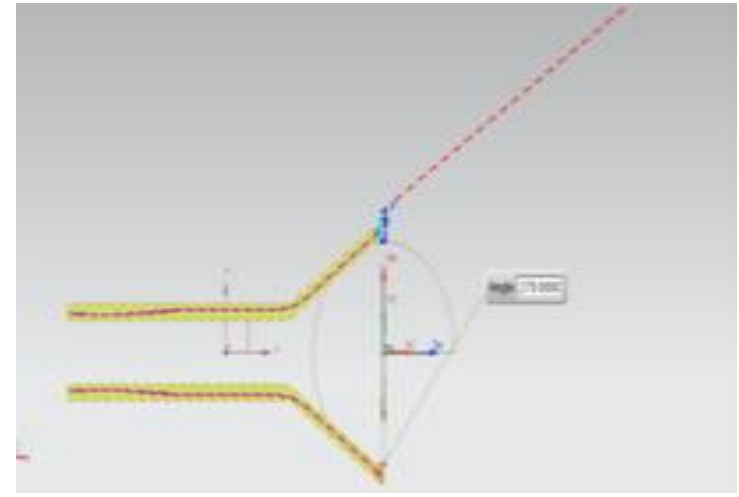

Fig. No. 5: Creation of facing operation

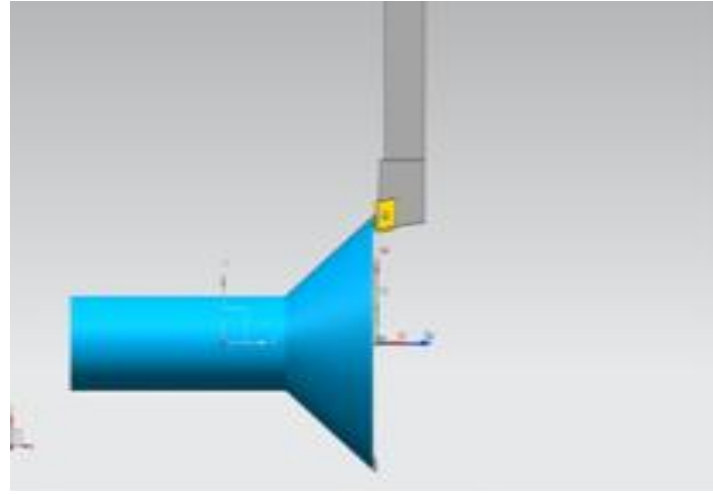

Fig. No. 6: Verification of facing operation

The below image named as figure no. 7 and 8 shows the creation and verification of OD_ROUGH operation on spike model respectively, maintaining speed of $1200 \mathrm{rpm}$ and feed $0.25 \mathrm{~mm} /$ revolution.

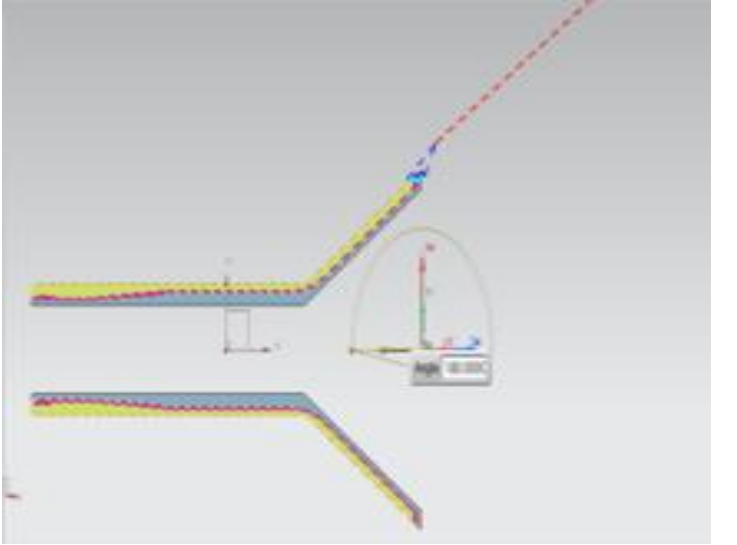

Fig. No. 7: Creation of OD_Rough_Turn operation

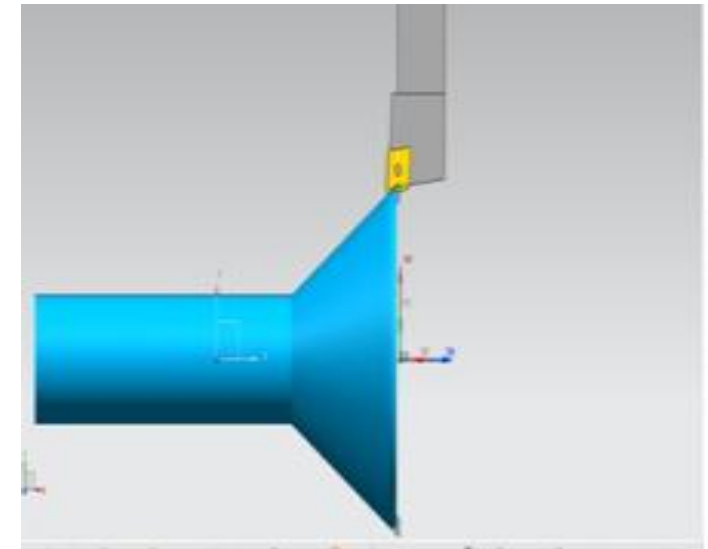

Fig. No. 8: Verification of OD_Rough_Turn

The ID_ROUGH operation on spike model is created at a speed of $1200 \mathrm{rpm}$ and feed $0.25 \mathrm{~mm} /$ revolution and the verification of ID_Rough operation is done and shown in below figure no. 9 . 


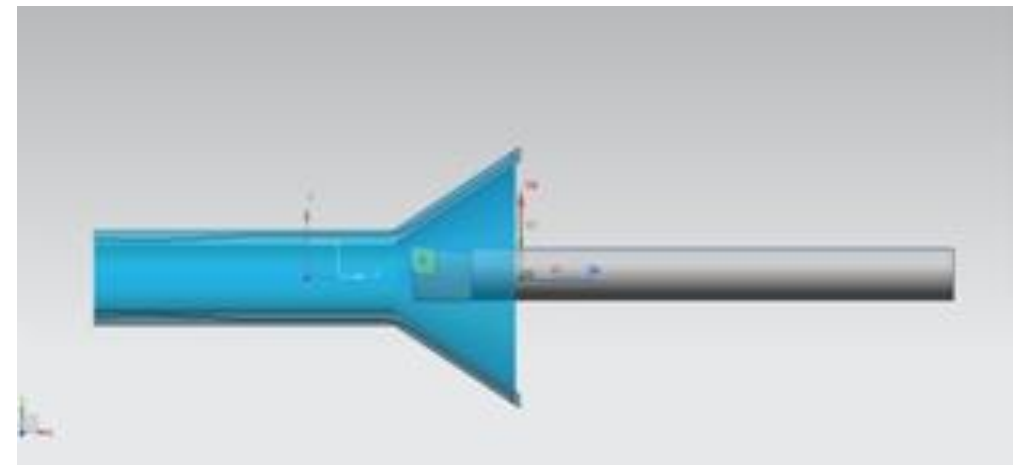

Fig. No. 9: Verification of ID_Rough operation

\section{Set_up_2 tool path generation}

The FACING operation on spike model is created by maintaining speed of 1200rpm and feed 0.25 $\mathrm{mm} /$ revolution illustrated in figure no. 10. And figure no. 11 shows the verification of the facing operation of the spike component.

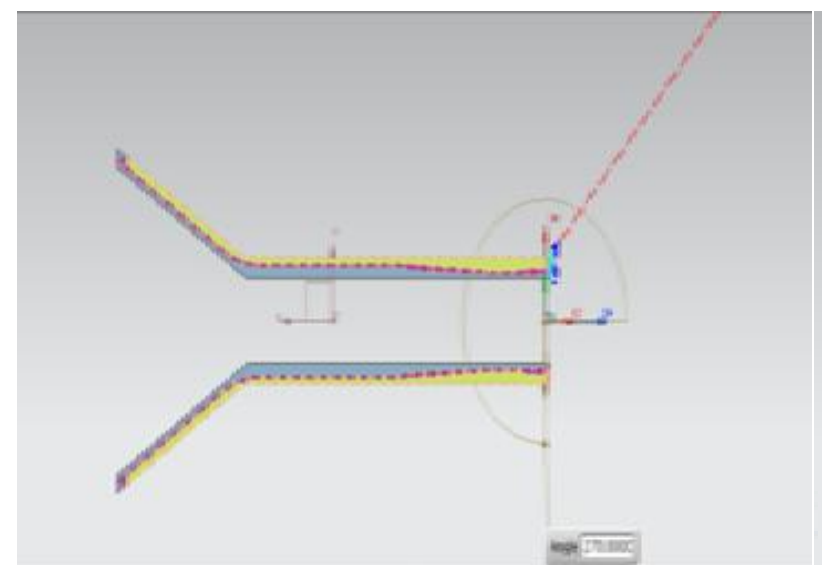

Fig. No. 10: Facing operation

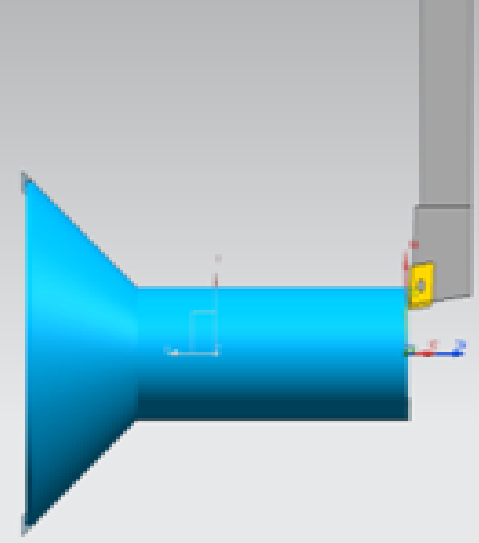

Fig. No. 11: Verification of facing operation

The OD_ROUGH operation on spike model is created while maintaining the speed at $1200 \mathrm{rpm}$ and feed 0.25 $\mathrm{mm} /$ revolution and it is being verified and verification of OD_Rough operation shown below in figure no. 12 . The drilling operation on spike model is done at maintaining speed at $1200 \mathrm{rpm}$ and feed $0.25 \mathrm{~mm} / \mathrm{revolution}$ and verified which is shown in below figure 13 .

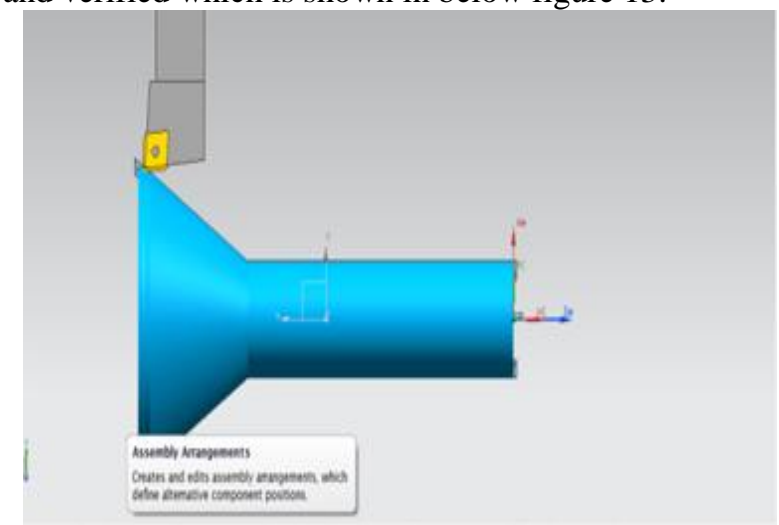

Fig. No. 12: Verification of OD_Rough operation

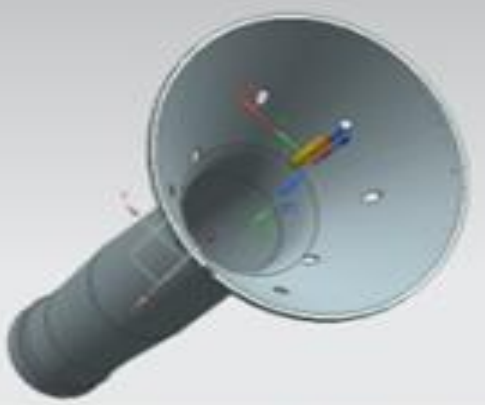

Fig. No. 13: Verification of Drilling operation

\section{PROGRAM NAME: PROGRAM}




\begin{tabular}{|l|l|l|}
\hline FACING & turning/FACING & OD_80_L_3 \\
\hline ROUGH_BORE_ID & turning/ROUGH_BORE_ID & ID_80_L_ROUGH \\
\hline ROUGH_TURN_OD & turning/ROUGH_TURN_OD & OD_80_L_1 \\
\hline DRILL_DIA_4.2 & drill/DRILLING & DRILLING_DIA_4.2 \\
\hline
\end{tabular}

PROGRAM NAME: PROGRAM_1

\begin{tabular}{|l|l|l|}
\hline OPERATION NAME & OPERATION DESCRIPTION & TOOL NAME \\
\hline FACING_SETUP_2 & turning/FACING & OD_80_L_SETUP_2 \\
\hline ROUGH_TURN_OD_SETUP_2 & turning/ROUGH_TURN_OD & OD_80_L_2 \\
\hline
\end{tabular}

\section{MANUFACTURING PROCESS OF SPIKE SUPPORT ON CNC MACHINE}

Raw material is placed on the machine, and degree of freedom is being arrested using fixtures. The Facing operation is general operation which is done for any component, after facing internal operations are done on the spike support.

First step: Facing operation is done on the raw material

Second step: Internal roughing operation provided on the component

Third step: The designed mandrel is fixed internally in the spike component and external roughing is done.

Fourth step: The component is fixed reversely in the fixture and setup_2 operations are done. Outer roughing operation is done.

Fifth step: Drilling operation is done on final turning component.

Final component after manufacturing: The final 3D model of the spike component is created after the manufacturing and shown in figure no. 14 as illustrated below.

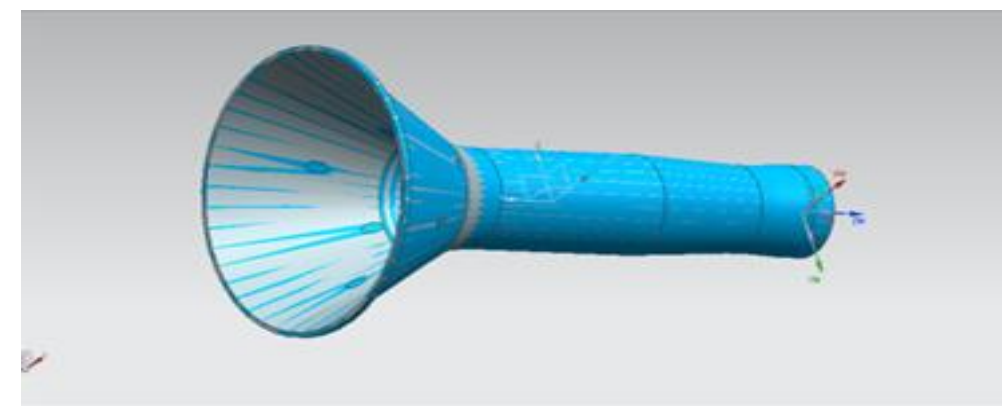

Fig. No. 14: 3D Model of the surface spike support after manufacturing

It has been found that surface finish is not obtained by using non-expandable designed mandrel, due to the gap between the mandrel and spike component. At high cutting speeds, the tool load is directly applied on the spike component and thus, scratches are formed due to the gap between the spike component and mandrel. Hence, the rejection rate increases due to the poor surface finish. In order to overcome from this rejection rate expandable mandrel is designed for spike support.

Design of expandable mandrel: Spike support is again machined by using expandable mandrel. After completion of internal operation expandable mandrel is used as jig which is shown in the figure 15. Expandable mandrel expands inside the spike component and makes contact which supports the component at high cutting speeds and gives better surface finish. The cutting speed preferred to get high surface finish is between 600$1800 \mathrm{rpm}$ which is obtained from analysis report. The Final component with better surface finish of spike support using expandable mandrel is obtained and shown in below figure no. 16 . 


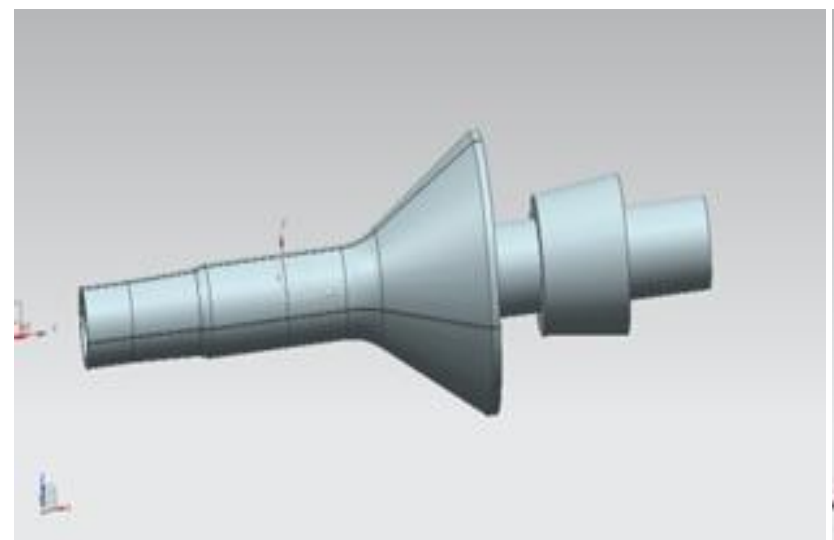

Fig. No. 15: Assembly of expandable mandrel

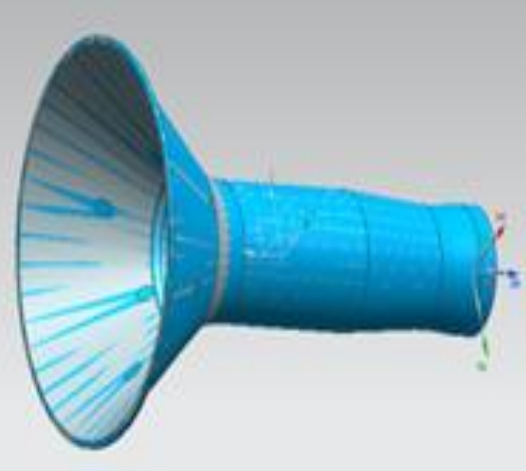

Fig. No. 16: Final component of spike support

\section{REDUCTION OF REJECTION RATE AND REWORKS RATE}

Reducing rejection rate and reworks rate using, 5-why (or) why-why analysis [17] [18][19] helps in increasing the production rate of any industry.

5-why analysis (or) why-why analysis: It's a method of questioning which leads to identification of the root cause(s) of the problem and is being conducted for identification of solutions to a problem that address it's root cause(s). Rather than taking actions that are merely band-aids, a why-why helps to identify the prevention of the issue from happening again.

Root Causes of Rejection Rate in manufacturing of spike support:

* Spike support is thin walled component, thus difficult to manufacture. Thus, Rejection rate is more due to equipment problem such as component setup, assigning improper tools, fixture design.

* Use of improper design of mandrel also causes the rejection rate of the component..

* Going for high cutting speed which are not preferred for machining spike component in order to reduce machining time.

* Due to procedure of machining i.e. mistakes in sequence of operations like Turning, and Drilling is also a factor to increase the rejection rate.

To reduce rejection and reworks the following aspects is taken up and they are:

* To reduce rejection rate, thin walled component is manufactured in the sequence i.e. internal operation firstly and further external operations by using mandrel support.

* Proper tools are specified which support machining thin walled component.

* Harmonic analysis is being performed to determine the optimum speed of the tool.

* Redesign of mandrel is done to reach high surface finish without fail.

\section{RESULTS \& DISCUSSION}

Graphical representation of rejection and reworks rate

The below graphs shows the rejection and reworks rate before WHY-WHY analysis and after WHY-WHY analysis.

Results before WHY-WHY analysis

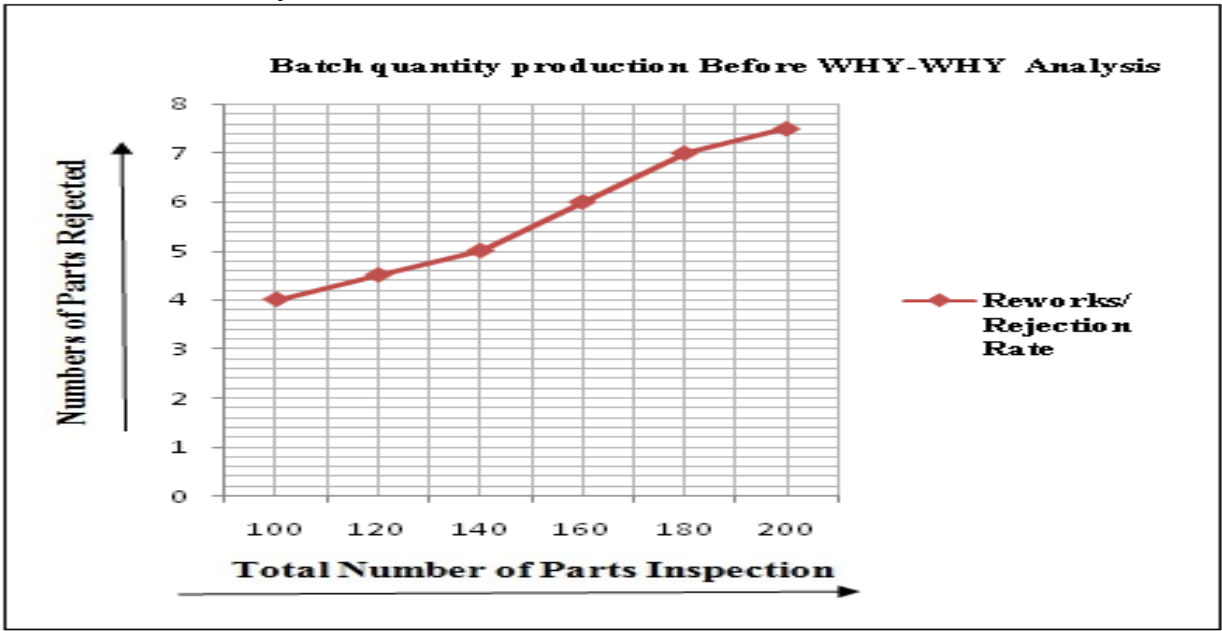

Graph 1: Results before WHY-WHY analysis 


\section{Results after WHY-WHY Analysis}

These four causes for rejection which are mentioned above is rectified by using WHY-WHY Analysis. The following graph indicates rejection rate after WHY-WHY Analysis.

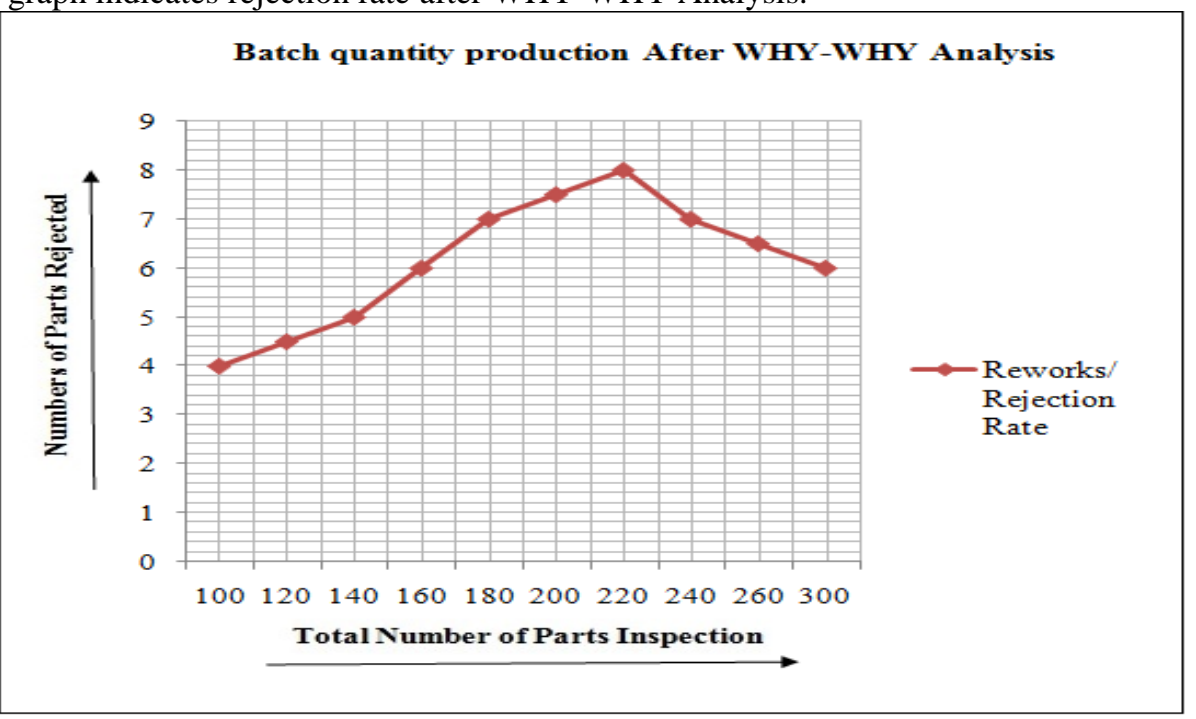

Graph 2: Results after WHY-WHY Analysis

From the above result graphs it is concluded that the reworks and rejection rate is decreased from $9 \%$ to $6 \%$ after using WHY-WHY Analysis.

\section{CONCLUSION}

In this project the optimum process plan to manufacture the support component was done which will reduce rejection and rework rate.CAD and CAM softwares were used to achieve the optimum manufacturing process plan. Initially, process plan and NC program was generated using NX-CAM software. A WHY-WHY (or) 5WHY analysis was done to reduce rejection and rework rate. Later a mandrel was designed and a new process plan and NC program was generated. From the comparison it is concluded that the process plan with the use of mandrel is more optimum which will reduce rejections and also reduce production cost.

\section{REFRENCE}

[1] C. Matthews, Aeronautical engineer's data book (2nd edition, Butterworth-Heinemann. p. 229, ISBN 978-0-7506-5125-7, 2005)

[2] D. M. Hosking, N. Anderson, Organizational change and innovation( Taylor \& Francis, p. 240, ISBN 978-0-415-06314-2, 1992)

[3] F. Kreith, The CRC handbook of mechanical engineering (CRC Press. p. 15-1, ISBN 978-0-8493-9418-8, 1998).

[4] F. Pichler, R. M. Díaz, Computer aided systems theory( Springer p. 602, ISBN 978-3-540-55354-0, 1992)

[5] J. Daintith, A dictionary of computing (5 edition, Oxford University Press. p. 102, ISBN 978-0-19860877-6, 2004).

[6] G. Boothroyd, W. A. Knight, Fundamentals of machining and machine tools (3rd edition, CRC Press. p. 401. ISBN 978-1-57444-659-3,2006).

[7] T. Govindaiah, et. al., "Design and Optimization of Fixture for Mirror Holder to Get High Surface Finish and Reduce Machining Time", SSRG International Journal of Mechanical Engineering (SSRG-IJME) volume-1,Issue 6, October 2014

[8] P M. Babu, K Srineevas, "Reduction of Reworks and Rejections in Manufacturing of a Thin Walled Aerospace Component” IJMERR, ISSN 2278 -0149 Vol. 3, No. 4, pp-604-611, October, 2014

[9] H. Wang, Y.(Kevin) Rong "Case Based Reasoning Method for Computer Aided Welding Fixture Design” Computer-Aided Design, Vol. 40 Issue 12, pp 1121-1132 (December 2008)

[10] I. Boyle, Y. Rong, D. Brown, "A REVIEW AND ANALYSIS OF CURRENT COMPUTER AIDED FIXTURE DESIGN APPROACHES”, Robotics and Computer-Integrated Manufacturing , pp. 1-12, May 2010

[11] J. C. Trappey, C. R. Li “A LITERATURE SURVEY OF FIXTURE DESIGN AUTOMATION”, The International Journal of Advanced Manufacturing Technology, pp. 240 - 255, 1990. 
[12] N. P. Maniar, D. P. Vakharia, "DESIGN \& DEVELOPMENT OF FIXTURE FOR CNC-REVIEWS, PRACT ICES \& FUTURE DIRECTIONS”, International Journal of Scientific \& Engineering Research Volume 4, Issue 2, February-2013.

[13] H. Wang, Y. Kevin Rong, H. Li, P. Shaun, Computer aided fixture design: Recent research and trends, Computer-Aided Design, Vol. 42, Issue 12, pp 1085-1094(2010)

[14] O. B. Toon, J. B. Pollack - A Global Average Model of Atmospheric Aerosols for Radiative Transfer Calculations. J. Appl. Meteor, -vol 15, 225-246, 1976.

[15] S. Naing et. al. "Design for Tooling to Enable Jigless Assembly - An Integrated Methodology for Jigless Assembly," SAE Technical Paper 2000-01-1765, doi: 10.4271/2000-01-1765, 2000.

[16] Y. Kang, Y. Rong, J. Yang, W. Ma, "Computer-aided fixture design verification", Assembly Automation, Vol. 22 Iss: 4, pp.350-359(2002)

[17] K. Bulsuk. An Introduction to 5 -Why. Karn Bulsuk: Full Speed Ahead, Published online March 2009. See http://www.bulsuk.com/2009/03/5-why-finding-root-causes.html

[18] "Five Whys Technique". adb.org. Asian Development Bank. February 2009. Retrieved 26 March 2012.

[19] "5-why Analysis using an Excel Spreadsheet Table". Retrieved 25 December 2010

[20] Taiichi Ohno; foreword by Norman Bodek (1988), "Toyota production system: beyond large-scale production", Portland, or: Productivity Press. ISBN 0-915299-14-3.

[21] The "Thinking" Production System: TPS as a winning strategy for developing people in the global manufacturing environment", Retrieved 2014-02-19. 